\title{
Chronic pain and cognition
}

\section{Dor crônica em cognição}

Sonia MD Brucki

\author{
Universidade de São Paulo, Grupo \\ Cognitivo e Comportamental, São \\ Paulo SP, Brasil. \\ Correspondence: \\ Sonia MD Brucki; Rua Rio Grande, \\ 180;04018-001 São Paulo SP, Brasil; \\ E-mail:sbrucki@uol.com.br \\ Conflict of interest: \\ There is no conflict of interest to \\ declare. \\ Received 06 April 2016 \\ Accepted 07 April 2016 \\ (cc) BY
}

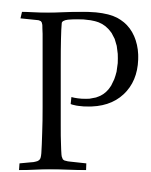

ain is a very frequent condition in worldwide population. In low- and middle-income countries the prevalence of any type of chronic pain is $33 \%$ in adult population, $56 \%$ in elderly population, and $35 \%$ in workers ${ }^{1}$. Considering chronic widespread pain, we have observed estimates around $10 \%$ to $15 \%$, with higher prevalence in women and in those with more than 40 years ${ }^{2}$.

Pain is one of the main causes of absence at work and it affects productivity and burden of disease. In a recent report by the Global Burden of Disease Study 2013, among 188 countries, leading causes of years lived with disability (YLD) were low back pain and major depressive disorder among the top ten causes of YLDs in every country. Back pain was the leading cause of YLDs in 86 countries and the second or third leading cause in 67 countries. In Brazil, it was the first cause, while neck pain was the $8^{\text {th }}$ cause of YLDs ${ }^{3}$.

Many studies have correlated pain with cognitive impairment. Many biases could concur for these. Pain killers with important central nervous system action, anxiety, depression, and other co-morbidities, as cancer or chronic diseases.

Ferreira et al. ${ }^{4}$, in this issue, have reported cognitive evaluation of patients with chronic pain and determined the main confounder factors observed to be associated with cognitive impairment.

Two systematic reviews and meta-analyses have evaluated studies evolving impairment of working memory and executive functions in people with chronic pain; both have revealed many biases among included studies, mainly due to lack of blinding to outcome. Working memory has been evaluated by different instruments, revealing heterogeneity through studies. Executive dysfunction is an umbrella, with many sides and with very heterogeneous evaluation and results ${ }^{5,6}$.

Other factors are correlated to possible cognitive impairment in pain sufferers, one of them is physical inactivity. We know that physical exercise is good for a better cognitive maintenance ${ }^{7}$; and a systematic review with 1,159 older adults has showed that subjects with chronic pain have had a significantly lower level of physical activity compared with 576 elders without chronic pain8.

We can observe through studies that a huge amount of different methods has been used to evaluate cognitive performance, sometimes studies have utilized validated instruments, some of them have used self-report measures, and others neuropsychological instruments. Most of these instruments have not been validated for pain patients9.

Thickness of dorsolateral prefrontal cortex and ventromedial prefrontal cortex are associated with complex regional pain syndrome, with thinner cortex in patients in relation to controls. These structural differences can explain executive dysfunction observed in these patients with chronic pain ${ }^{10}$.

A long follow-up study has observed that pain and depressive symptoms have been significantly associated; despite aging and frailty ${ }^{11}$. Any study that figures out cognition and pain must control depressive symptoms, like the study conducted by Ferreira et al. in this issue.

Ferreira et al. ${ }^{4}$ evaluated 45 patients with chronic pain matched by age, gender and schooling to 45 controls without pain. The group with chronic pain had shown more frequency in major depressive disorder, generalized anxiety disorder, unrefreshed sleep, and hypothyroidism. Cognitive evaluation had revealed significant differences in MoCA test (total score), verbal fluency, clock drawing, and in all measures of Stroop Test, the control group outperformed chronic pain group. Summarizing, measures of general cognition, executive function, planning, visuospatial function, processing speed, and response inhibition.

According to authors, this study is the first in Brazil. More studies are necessary, with more comprehensive cognitive evaluation, with a larger number of patients, to permit analyses with 
different pain duration, pain intensity, and etiologies. It is a valuable study in this field in our country.

There are many potential biases, when we study cognitive function and pain: duration (acute versus chronic), intensity of pain, personality traits, humor disorders, sleep disturbances, type of analgesics (opioid use, for example), etiology of pain (back pain due to osteoarthrosis, multiple sclerosis, polyneuropathy, fibromyalgia), age, gender, religious influence, and life style. For these reasons, besides heterogeneous evaluation instruments, different diagnostic criteria for chronic pain, and different cognitive domains included in the studies, research in this field is complex and remains a great challenge.

\section{References}

1. Jackson T, Thomas S, Stabile V, Han X, Shotwell M, McQueen K. Prevalence of chronic pain in low-income and middle-income countries: a systematic review and meta-analysis. Lancet. 2015;385 Suppl 2:S10. doi:10.1016/S0140-6736(15)60805-4

2. Mansfield KE, Sim J, Jordan JL, Jordan KP. A systematic review and meta-analysis of the prevalence of chronic widespread pain in the general population. Pain. 2016;157(1):55-64. doi:10.1097/j.pain.0000000000000314

3. Global Burden of Disease Study 2013 Collaborators. Global, regional, and national incidence, prevalence, and years lived with disability for 301 acute and chronic diseases and injuries in 188 countries, 1990-2013:a systematic analysis for the Global Burden of Disease Study 2013. Lancet. 2015;386(9995):743-800. doi:10.1016/S0140-6736(15)60692-4

4. Ferreira KS, Oliver GZ, Thomaz DC, Teixeira CT, Foss MP. Cognitive deficits in chronic pain patients, in a brief screening test, are independent of comorbidities and medication use. Arq Neuropsiquiatr. 2016;74(5):361-6. doi:10.1590/0004-282X20160032.

5. Berryman C, Stanton TR, Bowering JK, Tabor A, McFarlane A, Moseley LG. Evidence for working memory deficits in chronic pain: a systematic review and meta-analysis. Pain. 2013;154(8):1181-96. doi:10.1016/j.pain.2013.03.002
6. Berryman C, Stanton TR, Bowering JK, Tabor A, McFarlane A, Moseley GL. Do people with chronic pain have impaired executive function? A meta-analytical review. Clin Psychol Rev. 2014;34(7):563-79. doi:10.1016/j.cpr.2014.08.003

7. Brucki SMD. Does prevention for Alzheimer's disease exist? Dement Neuropsychol. 2009;3(3):209-13.

8. Stubbs B, Binnekade TT, Soundy A, Schofield P, Huijnen IP, Eggermont $\mathrm{LH}$. Are older adults with chronic musculoskeletal pain less active than older adults without pain? A systematic review and meta-analysis. Pain Med. 2013;14(9):1316-31. doi:10.1093/pm/pnv077

9. Ojeda B, Failde I, Dueñas M, Salazar A, Eccleston C. Methods and Instruments to evaluate cognitive function in chronic pain patients: a systematic review. Pain Med. 2015; pii:pnv077. doi:10.1093/pm/pnv077

10. Lee DH, Lee KJ, Cho Kl et al. Brain alterations and neurocognitive dysfunction in patients with complex regional pain syndrome. J Pain. 2015;16(6):580-6. doi:10.1016/j.jpain.2015.03.006

11. Sanders JB, Comijs HC, Bremmer MA, Deeg DJ, Beekman AT. A 13-year prospective cohort study on the effects of aging and frailty on the depression-pain relationship in older adults. Int J Geriatr Psychiatry. 2015;30(7):751-7. doi:10.1002/gps.4224 